\title{
Entre la tradición liberal y la revisión histórica. La construcción del pasado argentino a través de la correspondencia privada del historiador David Peña (1862-1930)
}

\section{Between the liberal tradition and the historical revision. The construction of the Argentine past through the private correspondence of the historian David Peña (1862-1930)}

\author{
María Gabriela Micheletti \\ Instituto de Historia, Universidad Católica Argentina \\ mgmicheletti@conicet.gov.ar
}

\section{Resumen}

Durante el siglo XIX fueron elaborados en Argentina los primeros relatos nacionales, los cuales desde una matriz liberal proporcionaron una imagen negativa de los caudillos provinciales. En este artículo se aborda el archivo epistolar del historiador David Peña, considerado un precursor en la revisión de esa construcción historiográfica, con el objetivo de indagar su postura frente a la tradición mitrista, y explorar sus nexos con escritores vinculados al revisionismo. Se parte del presupuesto de que la correspondencia personal resulta útil para conocer el pensamiento de un autor, reconstruir redes intelectuales y estudiar el circuito seguido por la difusión de ideas.

\section{Palabras clave}

Historiografía argentina, Correspondencia, Revisión histórica, David Peña, Bartolomé Mitre.

\begin{abstract}
The first national narratives elaborated in Argentina during the nineteenth century, from a liberal matrix provided a negative image of the provincial warlords. In this paper is analyzed the epistolar archive of historian David Peña, considered a pioneer in the revision of this historiographical construction, in order to investigate his position against the mitrista tradition, and to explore his relationships with writers linked to revisionism. It is assumed that personal correspondence is useful to know the thought of an author, to rebuild intellectual networks and to study the circuit followed by the diffusion of ideas.
\end{abstract}

\section{Key Words}

Argentine Historiography, Correspondence, Historical Revision, David Peña, Bartolomé Mitre. 


\section{Introducción}

En forma paralela a la construcción de los Estados nacionales latinoamericanos, como consecuencia de la ruptura del orden colonial y de las revoluciones de independencia, el siglo XIX vio emerger y desarrollarse historiografías nacionales que pergeñaron los primeros relatos de orígenes o "autobiografías" de los nuevos países en proceso de consolidación. Nombres como los de los historiadores José Manuel Restrepo (1781-1863), en Colombia, Carlos María de Bustamante (1774-1848), en México, Diego Barros Arana (1830-1907), en Chile, Bartolomé Mitre (1821-1906), en Argentina, o Francisco Varnhagen (1816-1878), en Brasil, han quedado vinculados a esos relatos que consiguieron inaugurar exitosas tradiciones historiográficas en sus respectivos países. En el ámbito rioplatense, en particular, la elaboración de una historia nacional fue más bien tardía, en comparación con lo sucedido en otras repúblicas latinoamericanas. Para Uruguay, puede rescatarse la obra de Francisco Bauzá (18491899), publicada a comienzos de la década de 1880. En el caso argentino, resalta la Historia de Belgrano y de la independencia argentina de Bartolomé Mitre, que si bien tuvo su primera aparición a fines de los años 50, fue recién con la tercera edición, de 1876, que adquirió su título, factura y rasgos definitivos. ${ }^{1}$ Junto al de Mitre, el otro gran relato nacional, elaborado por Vicente Fidel López (1815-1903) en diez tomos, comenzó a aparecer a partir de $1883 .^{2}$

Estos relatos convivieron, en sus inicios, con otros géneros literarios -memorias, autobiografías, ensayos, etc- con los que a menudo compartieron similares preocupaciones y visiones sobre el pasado. Fue precisamente desde la literatura que se había comenzado a forjar en la Argentina, a partir del célebre Facundo o Civilización y Barbarie (1845) de Domingo F. Sarmiento, una imagen negativa de los caudillos federales provinciales, a quienes con frecuencia se representaba como individuos ignorantes, crueles y bárbaros. ${ }^{3}$ En ellos se veía a los responsables de las guerras civiles y de la mayoría de los males que habían asolado al país durante las primeras décadas de vida independiente, y una verdadera rémora u obstáculo para la organización de la república.

\footnotetext{
${ }^{1}$ Fabio Wasserman, Entre Clío y la Polis. Conocimiento histórico y representaciones del pasado en el Río de La Plata (1830-1860) (Buenos Aires: Teseo, 2008); Fernando Devoto, "La construcción del relato de los orígenes en Argentina, Brasil y Uruguay: las historias nacionales de Varnhagen, Mitre y Bauzá", en Carlos Altamirano y Jorge Myers (coords.), Historia de los intelectuales en América Latina, vol. 1 (Buenos Aires: Katz, 2008), 269-289; y el Dossier "La Historia y la historiografía en América Latina en el siglo XIX. Perspectivas, configuraciones, itinerarios", Introducción por Tomás Sansón Corbo, Anuario del Instituto de Historia Argentina, 15 (UNLP, 2015).

${ }^{2}$ Fue Rómulo Carbia - uno de los integrantes de la llamada "Nueva Escuela Histórica"- quien a partir de 1925 cristalizó la idea de una historiografía argentina decimonónica organizada en torno a dos escuelas o tradiciones historiográficas dominantes y delimitadas por una fuerte polémica de orden metodológico entre ambas: la filosofante de V. F. López y la erudita de Mitre. En la segunda habría tenido su génesis una visión superadora que hacia 1916 se concretó en la Nueva Escuela. Rómulo Carbia, Historia crítica de la Historiografía Argentina (Buenos Aires: Coni, 1940), 121-165.

${ }^{3}$ Las tensiones presentes en el Facundo, y la disyuntiva no resuelta por Sarmiento -quien se inclina por la "y"- entre "civilización" y "barbarie", han sido puestas en relieve en un agudo trabajo por Oscar Terán, quien reflexiona acerca de la compleja relación entre ambas esferas: "aquello que caracteriza a la Argentina vista por Sarmiento es precisamente el encuentro, la interpretación, la fricción entre ellas, y no la existencia autónoma de la una sin la otra”. Oscar Terán, Para leer el Facundo. Civilización y barbarie. Cultura de fricción (Buenos Aires: Capital Intelectual, 2007).
} 
Estas ideas estuvieron presentes, también, al principiar el proceso de escritura de la historia, y Bartolomé Mitre las volcó en su primera versión de su Historia de Belgrano, difundida en la Galería de celebridades argentinas (1857). Aunque con el tiempo, y las sucesivas ediciones de su obra (1858-1859, 1876 y 1887), Mitre fue matizando su visión acerca de los caudillos y reconociéndoles algunos méritos, esa imagen negativa fue retomada por otros autores, como por el mencionado Vicente F. López, cuya Historia de la República Argentina (1883-1893) es considerada una acabada expresión de la historia testimonial y familiar de las elites porteñas. Esta representación del caudillismo, además, fue ampliamente difundida por los manuales escolares utilizados por un sistema educativo argentino en pleno proceso de consolidación. ${ }^{4}$

Fue frente a esa construcción histórica sobre el caudillismo, plasmada en clave a la vez cultural y política por la tradición liberal, que a principios del siglo XX un novel historiador realizó un proceso de revisión que (junto a los aportes que paralelamente realizaban algunos historiadores provinciales enmarcados dentro de un denominado "género reivindicatorio") posibilitó una progresiva revalorización del rol de los caudillos y de su contribución a la conformación del ordenamiento constitucional argentino. ${ }^{5}$ Se trata de David Peña (1862-1930), un rosarino radicado en Buenos Aires que, como profesor suplente de Historia Argentina en la Facultad de Filosofía y Letras, pronunció en 1903 una serie de conferencias que consiguieron agitar el ambiente intelectual de la universidad. Tres años después, esas clases se trasformaron en el libro Contribución al estudio de los caudillos argentinos. Juan Facundo Quiroga (1906).

David Peña, un intelectual "diletante" que se dispersaba entre las obras de carácter más estrictamente histórico, el género dramático, el periodismo y el ejercicio de la abogacía, y que fue clasificado por Rómulo Carbia entre los "ensayistas menores", 7 no puede ser equiparado en cuanto al volumen de su obra y a sus proyecciones con un

\footnotetext{
${ }^{4}$ Ver: Pablo Buchbinder, "Caudillos y caudillismo: una perspectiva historiográfica", en Noemí Goldman y Ricardo Salvatore (coords.), Caudillismos rioplatenses. Nuevas miradas a un viejo problema (Buenos Aires: Eudeba, 2005), 31-50.

${ }^{5}$ Las vindicaciones fueron concebidas -desde la misma tradición liberal-como alegatos documentados que procuraban restituir la memoria de personajes desprestigiados o ignorados en los relatos hegemónicos. Fernando Devoto y Nora Pagano, Historia de la historiografía argentina (Buenos Aires: Sudamericana, 2009), 53-56. En la línea de historiadores provinciales que rescataron las figuras de los caudillos locales pueden citarse: Ramón Lassaga, Historia de López (Buenos Aires: Imprenta de Mayo, 1881), Benigno Teijeiro Martínez, El general Francisco Ramírez en la historia de Entre Ríos (Buenos Aires: Imprenta de la "Nueva Revista de Buenos Aires", 1885), y Bernardo Frías, Historia del general Güemes y de la provincia de Salta (Salta: Establecimiento Tipográfico de "El Cívico", 1902). La diferencia entre estos relatos provinciales de difusión acotada y el de David Peña radicó en que éste logró situar la discusión en el ámbito porteño y consiguió generar una sonora repercusión de alcance nacional.

6 El término "diletante", aplicado a David Peña, fue utilizado por el diario La Unión en su nota necrológica. La Unión, 10 de abril de 1930, en David Peña (10 de julio de 1862 - 9 de abril de 1930). Juicios póstumos. Oraciones fúnebres. Pésames (Edición íntima, 1930), 28.

7 Escribe Carbia: “[...] estos ensayos menores son tales porque circunscriben a un personaje, a un episodio o a un detalle, todo el campo de la observación. Muchos se desenvuelven en franca actitud de alegato, y no pocos pecan por exceso de preocupación literaria". Estas características estarían presentes en el Juan Facundo Quiroga, que fue considerado por Carbia un "ensayo reivindicatorio". R. Carbia, Historia crítica, 280.
} 
Mitre o un López. ${ }^{8}$ Sin embargo, ya algunos de sus contemporáneos pudieron vislumbrar las notas singulares que encerraba su obra en cuanto a su capacidad para confrontar con los autores consagrados, y que más tarde fueron puestas en relieve por los historiadores de la historiografía. ${ }^{9}$ De hecho, su Juan Facundo Quiroga ha sido considerado un punto de inflexión en la evolución de la imagen construida por la historiografía acerca del caudillismo decimonónico. ${ }^{10}$

Esta característica de "bisagra" reconocida a su obra, abre el interrogante de hasta qué punto David Peña realmente pretendió entrar en tensión con la tradición liberal ${ }^{11}$ y en qué medida procuró posicionarse como un "revisionista". ${ }^{12}$ En busca de una repuesta, este artículo hace opción por los textos de carácter privado del autor y explora en su archivo epistolar, ya que parte del presupuesto de que en las cartas, en tanto "escrituras del yo", la expresión autobiográfica y la testimonialidad alcanzan un lugar central, y de que a través de ellas incluso puede quedar expuesto el criterio de un autor sobre un tema histórico, científico o literario. A la vez, la correspondencia permite saber con qué otros intelectuales un escritor se carteaba y ayuda a delinear el camino o circuito seguido por la difusión de las ideas. ${ }^{13}$

\footnotetext{
${ }^{8}$ Para una caracterización del momento historiográfico transcurrido entre 1880 y la época del Centenario de la Revolución de Mayo y la posición hegemónica que durante ese lapso mantuvieron las obras de Mitre y V. F. López: Tulio Halperín Donghi, "La Historiografía: treinta años en busca de un rumbo", en Gustavo Ferrari y Ezequiel Gallo (comps.), La Argentina del Ochenta al Centenario (Buenos Aires: Sudamericana, 1980), 829-840.

${ }^{9}$ Estanislao Zeballos (1854-1923), destacado intelectual y político argentino del período de entresiglos, escribió sobre Peña en momentos previos a la aparición del libro: "Cualesquiera que sea el juicio definitivo sobre su trabajo, digno de una crítica acrisolada, él rompió el silencio y la inacción reinantes en materia de historia nacional. Cristalizada ésta en las obras prestigiosas de Mitre y de López y en algunas monografías o biografías, la obra del historiador argentino, apenas abierta, está paralizada. [...] La obra próxima a aparecer del doctor Peña [abre] el debate y la comprobación sobre una época trágica e interesantísima de la vida nacional, a la vez que [trae] a juicio la propaganda libertadora y sociológica, turbulenta, apasionada, pero fundadora de Sarmiento, con sus grandes y resplandecientes bocetos de hombres y de caracteres". "Juan Facundo Quiroga", Revista de Derecho, Historia y Letras, t. XXIV (1906): 498.

${ }^{10}$ El mismo Carbia admite que el libro de Peña logra demostrar su tesis principal, consistente en probar que el Facundo de Sarmiento ha falseado la historia. Más aún, agrega que "su importancia, en verdad, es doble: inicia entre nosotros la revisión del valor testimonial de nuestros dioses mayores y aporta un haz de luces para la cumplida visión de uno de los panoramas históricos más importantes y menos estudiados a fondo en nuestro país". R. Carbia, Historia crítica, 282-283. En tiempos recientes, la obra de Peña ha sido justipreciada, entre otros, por: Pablo Buchbinder, "Caudillos", 42-43; Fernando Devoto y Nora Pagano, Historia, 204-205; y José Carlos Chiaramonte, "Revisión del revisionismo: orígenes del revisionismo histórico argentino", en Id., Usos políticos de la historia. Lenguaje de clases y revisionismo histórico (Buenos Aires: Sudamericana, 2013), 153-154.

${ }^{11}$ En el presente artículo se hace referencia a la "tradición liberal" en forma general y desde una perspectiva historiográfica, sin desconocer el carácter heterogéneo del liberalismo argentino de entresiglos. Para profundizar en las diversas vertientes del liberalismo -de conservadores a radicales, de católicos a positivistas, etc.- se recomienda consultar, entre otros: Eduardo Zimmermann, Los liberales reformistas. La cuestión social en la Argentina. 1890-1916 (Buenos Aires: Sudamericana, 1995), y Ezequiel Gallo, “Tradición liberal argentina”, Revista Estudios Públicos, 27 (1987): 351-378.

${ }^{12}$ El término "revisionista" se emplea en sentido amplio, y no circunscripto al movimiento historiográfico que tuvo inicio en Argentina a comienzos de los años 30.

${ }^{13}$ Debido a las posibilidades abiertas por el género epistolar, en los últimos años éste ha adquirido una creciente importancia para los estudios de historia cultural e historia intelectual. Entre otros, consultar: Antonio Mestre Sanchis, "La carta, fuente de conocimiento histórico", Revista de Historia Moderna, 18 (2000): 13-26; Françoise Simonet-Tenant, “Aperçu historique de l'écriture épistolaire: du social à
} 
El objetivo consiste entonces en indagar, a través del análisis de la correspondencia que se conserva en el Fondo David Peña de la Academia Nacional de la Historia (Argentina), cuál fue la posición asumida por este autor frente a la tradición mitrista, de cuño liberal y de gran vigencia en el período de entresiglos, y a la vez determinar sus posibles nexos con escritores vinculados al llamado revisionismo historiográfico. Con ello se espera aportar, asimismo, al conocimiento de una personalidad aún poco estudiada dentro del marco de la historia de la historiografía.

\section{Una mirada de conjunto al epistolario de David Peña}

En su archivo personal, David Peña recopiló una buena cantidad de cartas que dan cuenta del itinerario epistolar que forjó en su interrelación con otros historiadores y letrados de su época. ${ }^{14}$ Algunas, mantenidas con corresponsales frecuentes, traslucen una relación de amistad sostenida en el tiempo, refrendada por explícitas muestras de afecto. Otras, circunspectas y puntuales, revelan el contacto por algún asunto en concreto. En su conjunto, sirven para desnudar la nutrida trama de relaciones tejida con paciencia y a lo largo de décadas por Peña, y por la que desfilan múltiples y destacadas figuras de la intelectualidad de entresiglos. No faltan en su archivo los contactos epistolares mantenidos con historiadores consagrados ya a fines del siglo XIX, como el mencionado Bartolomé Mitre o el erudito Paul Groussac. Ni tampoco, las cartas que ponen de manifiesto los nexos que se iban tendiendo con historiadores que encarnaban al igual que Peña, aunque desde un amplio arco de ideas- posiciones de revisión de la historia, como Adolfo Saldías, José Ingenieros, Ernesto Quesada, Ricardo Rojas, Carlos Ibarguren, Manuel Gálvez y los paraguayos Juan E. O’ Leary y Juan Stefanich. Algunas cartas evidencian los contactos formales y correctos con las autoridades de instituciones dedicadas a la Historia o de otras asociaciones, como Ricardo Levene, Antonio Dellepiane, Mariano de Vedia y Mitre y Manuel Carlés. Otras, revelan la extrema confianza y simpatía existentes entre Peña y el político radical y librepensador Francisco Barroetaveña. También hay que contar entre los corresponsales de Peña, a algunos otros historiadores de relieve, como Estanislao Zeballos, Mariano Pelliza, Ramón Cárcano, Pastor Obligado, Adolfo J. Carranza, Lucas Ayarragaray, Pedro S. Lamas, Enrique Peña y Carlos Correa Luna, y a escritores como el católico nacionalista Gustavo Martínez Zuviría. Por fin, un núcleo de cartas desgranan el intercambio epistolar nacido del profundo cariño y admiración sentido por David Peña hacia uno de los políticos y letrados más lúcidos e influyentes del siglo XIX argentino: el inspirador de la Constitución Nacional, Juan Bautista Alberdi. ${ }^{15}$

De entre estos caracterizados corresponsales de Peña, y teniendo en cuenta el cariz polémico que le ha sido reconocido al Juan Facundo Quiroga y que ha sido indicado más arriba, en este artículo se ha decidido hacer un recorte centrado en el análisis de las

l'intime", Le français aujourd'hui, vol. 147, 4 (2004): 35-42; y Laura Fernández Cordero, "Cartas y epistolarios. Lecturas sobre la subjetividad", Políticas de la Memoria, 14 (2013/2014): 23-29.

${ }^{14}$ Archivo de la Academia Nacional de la Historia (AANH), Fondo David Peña (FDP).

${ }^{15}$ La caracterización del epistolario de David Peña ha sido encarada en el artículo: "“Un epistolario que puede ser considerado como elemento de historia'. Amistades personales, sociabilidades intelectuales y proyectos editoriales a través de las cartas del archivo de David Peña (1862-1930)", Anuario del Centro de Estudios Históricos "Prof. Carlos S. A. Segreti”, 16 (en prensa). 
cartas intercambiadas, por un lado, con los Mitre (tanto con Bartolomé, como con su hijo Emilio) y, por otro lado, con algunos escritores afines a posturas de revisión histórica, con el propósito de avanzar hacia una más precisa definición de la posición historiográfica en la que puede ser ubicado este autor del período de entresiglos.

\title{
Los comienzos: un interlocutor insoslayable y esquivo
}

Existen motivos para sostener que Bartolomé Mitre (1821-1906) y David Peña no eran, ni personal ni intelectualmente hablando, particularmente afines. Más allá de la distancia generacional - que sin embargo no fue obstáculo en Peña para mantener una conocida relación de amistad y aprecio con Juan Bautista Alberdi (1810-1884)-, otras circunstancias distanciaban al influyente político y expresidente del joven escritor. Entre estas circunstancias cabe mencionar, precisamente, la encendida y pública defensa que hizo Peña de Alberdi, a quien el mitrismo había rotulado de "traidor" a la patria por haberse manifestado contrario a la Guerra de la Triple Alianza contra el Paraguay. ${ }^{16} \mathrm{~A}$ ello deben sumarse ciertas posiciones historiográficas que fue asumiendo Peña, en divergencia con la tradición iniciada por Mitre y otros escritores decimonónicos acerca de las guerras civiles y los caudillos federales del interior. Peña, en sus escritos y desde su prédica periodística, significaba un cuestionamiento a la construcción histórica provista desde los círculos de poder, bien ejemplificada en la figura de Mitre, pieza clave de la organización del país bajo la primacía de Buenos Aires a partir de 1862, presidente durante los primeros años de la Guerra del Paraguay, actor y escritor a la vez de la historia de la nación argentina. ${ }^{17}$ A diferencia de Mitre, Peña -nacido en 1862, es decir, luego de Caseros y de Pavón-, se encontraba habilitado para hacer una lectura del pasado argentino más libre de ataduras y de compromisos políticos, aunque permeada, en todo caso, por la profunda marca intelectual impresa en él por Alberdi. Las tiranteces con Mitre se habrían iniciado temprano, por 1881, según un Peña de escasos diecinueve años le revelaba por carta al propio Alberdi, a la sazón en Londres:

\begin{abstract}
Aquel celebrado proyecto de redactar un periódico en los días que estaba ud. por irse, llevóse por fin a cabo, con las inmensas contrariedades que se presentan a todo empresario sin capital. La Revista Platense pasó a mis manos [...], y en su primer $n^{\circ}$ [...] se permitió el Redactor escribir párrafos desalineados e impuros sobre un personaje más impuro todavía. Todos vieron detrás del articulejo el insulto y detrás del personaje el monumento de la calle de San Martín, ${ }^{18}$ y al otro día el Administrador borraba 50 suscriptores mitristas de la lista de los favorecedores de mi desdichada Revista. Así empezó la vida, por no llamar la muerte, de mi diario. Para estar condenado a no seguir escribiendo sobre el Gral. Mitre como yo deseaba, para verla sujeta y esclava de las tendencias literarias de Buenos Aires, para no poder ocuparme en nada del amigo ausente, defendiendo en la humildísima esfera de un papelucho semanal sus méritos y dotes, he preferido, como el padre de Virginia, darle muerte al mes de su rápida aparición. ${ }^{19}$
\end{abstract}

\footnotetext{
${ }^{16} \mathrm{Al}$ respecto, véase David Peña, Alberdi, los mitristas y la guerra de la triple alianza, con Estudio preliminar de Rodolfo Ortega Peña y Eduardo Luis Duhalde (Buenos Aires: A. Peña Lillo, 1965).

${ }^{17}$ Halperín Donghi ha resaltado el papel historiográfico que desempeñó Mitre como responsable de erigir a la nación en sujeto principal de la historia argentina -en lugar de los múltiples sujetos individuales y colectivos que hasta entonces había tenido-, cuestión central para dotar a la historia de validez científica. Tulio Halperín Donghi, "Mitre y la formulación de una historia nacional para la Argentina", Anuario del IEHS, 11 (1996): 57-69.

${ }^{18}$ En su carta Peña se refiere a Mitre, cuya casa - actual Museo Mitre- se encontraba ubicada en la calle San Martín. Las palabras en cursiva se encuentran resaltadas en el original.

${ }^{19}$ AANH, FDP, caja 1, David Peña a Juan Bautista Alberdi, 22 de septiembre de 1881.
} 
En esa extensa carta, que comienza con una larga declaración de cariño filial de Peña hacia Alberdi, para pasar luego al relato transcripto sobre su primera publicación, existe aún un interesante comentario de carácter historiográfico en la última postdata: "El Dr. López (Don Vicente) está escribiendo actualmente unas refutaciones históricas contra Mitre. Me aseguran son tremendas, lo enloquecerán al grave arqueólogo sin compasión". ${ }^{20}$ Peña asumía así el singular rol de darle a Alberdi la primicia de la pronta aparición de la Refutación a las comprobaciones históricas sobre la Historia de Belgrano, en los momentos mismos en que estaba teniendo lugar en Buenos Aires la sonada polémica Mitre-López. La complicidad de Peña hacia Alberdi, en desmedro del enemigo de éste, se hace epistolarmente manifiesta.

Aunque las diferentes visiones sobre el pasado de Peña y de Mitre y las desinteligencias surgidas entre ambos a raíz de la defensa alberdiana encarada por el primero ya han sido apuntadas anteriormente por otros historiadores de la historiografía, y surgen de compulsar los discursos públicos de Peña, lo que se procura destacar aquí es que el estudio de sus textos de carácter privado -sus cartas- permite apreciar algunos matices en su posición frente al mitrismo. Así como este análisis ha posibilitado localizar el inicio de esa discrepancia en estrecha trabazón con el forjamiento del vínculo Peña-Alberdi, puede sostenerse que el epistolario de Peña correspondiente a los comienzos de su trayectoria intelectual deja en evidencia el respeto y el reconocimiento profesados hacia la autoridad del principal historiador de la época. Los esfuerzos del joven historiador por entablar una relación y por buscar la aprobación resultan manifiestos, al mismo tiempo que se percibe la distancia cortés mantenida por Mitre.

Se ha detectado un conjunto de cinco cartas intercambiadas entre 1888 y el año 1900, una dirigida por Peña a Mitre, y otras cuatro enviadas por Mitre en respuesta a alguna anterior del primero. Todas surgen a partir de alguna iniciativa de Peña por establecer contacto con un interlocutor que ya para el momento en que se dio el inicio de los intercambios era considerado insoslayable en materia historiográfica. Este prestigio de Mitre se había consolidado a través de las famosas polémicas que mantuvo con Dalmacio Vélez Sarsfield primero (1864), y luego con Vicente Fidel López (18811882), en un estadio historiográfico en el que, ante la ausencia de canales académicos de legitimación, "la crítica historiográfica se convirtió en el medio privilegiado para dirimir problemas vinculados a la competencia y legitimidad de aquellos que compartían el interés por dilucidar hechos del pasado". Esa crítica, además, se vinculaba con "la necesidad de dotar de una legitimidad histórica y jurídica al Estado nacional", lo que "contribuiría a otorgar un status social y científico a la historiografía". ${ }^{21}$ De esas polémicas, Mitre emergió como el principal referente de la historiografía erudita, que centró en la compulsa documental el requisito fundamental para encaminar una práctica hasta entonces imprecisa de la escritura de la historia en el Río de la Plata. No resulta casual entonces que David Peña, un joven animoso y con múltiples inquietudes culturales, que ya desde su época estudiantil había llamado la atención del presidente

\footnotetext{
${ }^{20}$ Ibid.

21 Alejandro Eujanian, "El surgimiento de la crítica", en Alejandro Cattaruzza y Alejandro Eujanian, Políticas de la historia argentina, 1860-1960 (Buenos Aires: Alianza Editorial, 2003), 18-19.
} 
Nicolás Avellaneda por su carácter decidido y su vivacidad, buscara la aquiescencia del reconocido historiador. ${ }^{22}$

La primera carta-respuesta de Mitre a Peña data de enero de 1888. En ella, el expresidente declina la invitación a ser colaborador en La Época, el periódico que Peña acababa de fundar en su ciudad natal, Rosario. Por entonces, David Peña era secretario personal de José Gálvez, quien fue gobernador de la provincia de Santa Fe (1886-1890) y líder del autonomismo provincial. Peña fundó y fue el primer director del diario oficialista Nueva Época (1886) de la ciudad de Santa Fe, y con el mismo espíritu procuró establecer un periódico en la importante ciudad ubicada en el sur provincial, conocida por su tendencia liberal y opositora. Al excusarse en su carta por no aceptar la invitación recibida, Mitre lo hace con argumentos de orden estrictamente historiográficos, ya que aduce falta de tiempo debido a la necesidad de dar término a trabajos que tiene entre manos, y menciona de manera especial su Historia de San Martín y de la emancipación sudamericana. Comenta que por el momento ha suspendido la publicación que hizo de algunos capítulos con el objetivo de dar una muestra del plan de la obra (el primer tomo apareció a fines de 1887), y anuncia la aparición del segundo tomo durante el año en curso (lo que efectivamente se concretó). ${ }^{23}$ Esta carta permite realizar dos reflexiones. Por un lado, ella muestra a un Mitre que no solo se preocupa por explicar su negativa, sino que también brinda espontáneamente información sobre su labor aún inédita, lo que es un indicio de que Peña no le resulta del todo indiferente. Por otro lado, no obstante las justificadas razones enunciadas, puede adivinarse la existencia también de otros motivos, de orden político, en la renuencia de Mitre a participar en un periódico que pretendía paliar la prédica opositora al galvismo de la prensa rosarina. No está de más recordar que esta tenía uno de sus principales bastiones en el diario $\mathrm{La}$ Capital, conocido precisamente por su adhesión al liberalismo mitrista. ${ }^{24}$ Cabe agregar que este emprendimiento editorial de Peña concluyó pronto en un fracaso, y luego de soportar duras críticas de los sectores opositores al gobierno provincial el diario fue cerrado en agosto de 1889.

La segunda carta-respuesta de Mitre, escrita en 1891, también tiene por motivo a uno de los proyectos editoriales llevados adelante por David Peña en Rosario. En este caso, la política no parece haber estado de por medio, ya que la fundación por parte de Peña de Revista Argentina (1891) -que llevaba por subtítulo: Historia Americana, Literatura, Legislación, Jurisprudencia y Administración-, respondió más bien al interés de dar a luz una publicación más "amable" que, alejada de los sinsabores que había despertado $L a$ Época, sirviera en la provincia como vínculo de sociabilidad intelectual. ${ }^{25}$ En este caso, Mitre se da por enterado de la aparición del primer número de Revista Argentina, le desea éxitos y elogia sus propósitos, aunque aclara que no le ha llegado el ejemplar que Peña le había remitido. Tampoco en este caso la publicación

\footnotetext{
${ }^{22}$ Leopoldo Kanner, David Peña y los orígenes del Colegio Nacional de Rosario (Rosario: Banco Provincial de Santa Fe. Casa Rosario, 1974), 62-64 y 122.

${ }^{23}$ AANH, FDP, caja 1, Bartolomé Mitre a David Peña, 3 de enero de 1888.

24 Miguel Ángel De Marco, Santa Fe en la transformación argentina. El poder central y los condicionamientos políticos, constitucionales y administrativos en el desarrollo de la provincia. 18801912 (Rosario: Museo Histórico Provincial "Dr. Julio Marc", 2001), 48.

${ }^{25}$ Wladimir Mikielievich, "Tropezones de dos pescadores de estrellas", Revista de Historia de Rosario, 33 (1981): 190-192.
} 
logró prosperar, y los ambiciosos objetivos trazados por Peña en el Prospecto solo se pudieron concretar en pequeña medida. ${ }^{26}$

Las últimas cartas del intercambio Mitre-Peña corresponden ya al final del siglo. Para entonces, David Peña acababa de regresar a la capital de la República para instalarse en ella definitivamente, y había sido nombrado profesor en la Facultad de Filosofía y Letras de la Universidad de Buenos Aires, de reciente creación (1896). ${ }^{27}$ La carta de 1899 es motivada por un nuevo envío de Peña a Mitre, en este caso de un libro, que consistía en una compilación de conferencias y trabajos encomendados a los alumnos de la Facultad, y al que Mitre agradece y promete conservar en su Biblioteca Americana. En esta carta, que es la más extensa de las cinco analizadas, Mitre se refiere a un documento sobre Güemes y San Martín que aparece citado en el libro y sobre el cual Peña le ha llamado la atención. ${ }^{28}$ Mitre minimiza su valor histórico debido a la ausencia de datos sobre su origen y autenticidad, y por no referirse a un hecho que haya tenido ejecución real, y aprovecha para explicar a Peña -en una actitud que denota criterio de autoridad y una relación asimétrica- algunas cuestiones sobre la situación de las provincias del Norte entre 1820 y 1821, en las que admite que se puede haber deslizado algún error de fechas porque escribe "de memoria". ${ }^{29}$ Tanto esta carta, como las circunstancias en las que fue redactada, fueron dadas a conocer públicamente por Peña en una nota al pie de su Juan Facundo Quiroga (1906). En dicha nota, si bien Peña se muestra entusiasmado por la rápida respuesta que de Mitre mereció su carta -lo que le sirve para legitimarse a sí mismo como historiador-, insiste acerca de los datos ciertos que pareciera contener el documento puesto por aquel en cuestión. ${ }^{30}$

Las otras dos cartas son de 1900, revisten carácter confidencial, y resultan reveladoras del posicionamiento a la vez respetuoso e independiente de Peña frente al mitrismo. En ellas se evidencia la ingenua audacia de Peña, que se atreve a escribir a Mitre con motivo del cumpleaños, para pedirle que presida una comisión que proyecta organizar con el objetivo de lograr que el monumento levantado a Alberdi en La Recoleta sea inaugurado públicamente y se depositen en él los restos del publicista (repatriados en 1889, pero depositados provisoriamente en otro lugar). Peña -a quien no se le escapa el valor reivindicativo que significaría una mínima muestra de reconocimiento por parte de Mitre hacia su antiguo enemigo- justifica su arrojada solicitud lisonjeando a su interlocutor:

\footnotetext{
${ }^{26}$ AANH, FDP, c. 1, Bartolomé Mitre a David Peña, 4 de junio de 1891, y María Gabriela Micheletti, "CComercio de pensamientos' entre 'soldados de la idea'. Comunicación cultural, sociabilidades intelectuales y escritura de la memoria en el Rosario y Santa Fe de entresiglos”, en Liliana Brezzo y Miguel De Marco (eds.), Historias en ciudades puerto (Rosario: IH / EDUCA, 2009), 105-145.

${ }^{27}$ Nacido en Rosario, por cuestiones familiares David Peña debió trasladarse de niño a Buenos Aires. Ya adolescente, regresó a su ciudad natal, en donde pudo completar su formación secundaria en el Colegio Nacional que acababa de ser establecido. Más tarde estudió Derecho en la Universidad de Buenos Aires, ciudad de la que se alejó nuevamente, pero a la que regresó para radicarse sobre el final del siglo XIX.

${ }^{28}$ La circulación e intercambio de documentos entre letrados fue una de las principales características del período previo a la etapa de profesionalización de la Historia en la Argentina. Véase Pablo Buchbinder, "Vínculos privados, instituciones públicas y reglas profesionales en los orígenes de la historiografía argentina", Boletín del Instituto de Historia Argentina y Americana "Dr. Emilio Ravignani”, 3ra. Serie, 13 (1996): 59-82.

${ }^{29}$ AANH, FDP, c. 1, Bartolomé Mitre a David Peña, 6 de diciembre de 1899.

${ }^{30}$ David Peña, Contribución al estudio de los caudillos argentinos. Juan Facundo Quiroga. Conferencias en la Facultad de Filosofía y Letras (con ampliaciones y notas) (Buenos Aires: Coni, 1906), 83-86.
} 


\begin{abstract}
Es evidente que el acto que esbozo envuelve el muy alto de señalar una vez más a las generaciones todas la grandeza de su alma de Ud., tan digna del propósito que se señala, y no quiero ocultar que es el más firme objeto mío organizar estos trabajos para demostrar que en las alturas de la vida y de la historia los espíritus superiores no se sienten agitados por pasiones de otra edad. Me dirijo al hombre que dio estas muestras de su abnegada serenidad moral en todos los momentos de su vida pública y privada y el único agregado que formulo a mi pensamiento es uno de difícil expresión literaria: cuán suprema impresión causará la actitud del general Mitre recogiendo a sus 80 años los recuerdos y despojos de sus más grandes adversarios, por haber designado la Providencia que él sobreviva a todos $[\ldots]^{31}$
\end{abstract}

Aquí queda claro que en la construcción historiográfica del pasado argentino lo que se encuentra en juego es determinar a quién compete decidir cuáles son las personalidades dignas de integrar el panteón nacional de próceres, a la vez que pujar por hacer entrar en él al que ha quedado excluido por decisión de los que se han encargado de escribir la historia nacional. Peña le reconoce esa autoridad a Mitre, pero a la vez procura torcer su posición a favor de su defendido. La respuesta de Mitre es la esperada. Agradece las cualidades que le atribuye Peña, pero se manifiesta "moralmente inhibido" de aceptar la designación que se le ofrece:

\begin{abstract}
En tal sentido, y en el caso a que Ud. se refiere mi actitud tiene que ser puramente pasiva, dejando que los argentinos que piensan de distinto modo respecto de la personalidad cuya memoria se trata de honrar, cumplan su propósito, sin que por mi parte pueda cooperar en favor de una manera ostensible, ni tampoco obstar a ello, haciendo el debido honor al patriotismo de los iniciadores. $^{32}$
\end{abstract}

Esta es la última carta que se ha identificado de la correspondencia intercambiada entre David Peña y Bartolomé Mitre. En ninguno de los intentos de acercamiento epistolar aquí analizados, Peña obtuvo del prestigioso historiador más que condescendientes palabras de cortesía, sin lograr involucrarlo en sus proyectos. Se puede ir más allá, al considerar que lo que estaba en juego en esta etapa historiográfica, "era la autoridad que el historiador reclamaba [...] con respecto a aquellos cuyo campo de estudio compartía, pero frente a los cuales intentaba afirmar su preeminencia y status". ${ }^{33}$ Es decir, que así como en las famosas polémicas en que intervino, también en sus intercambios epistolares Mitre habría buscado afirmar su autoridad para no ceder fácilmente a los requerimientos de un novel y audaz historiador como Peña. La carta en torno al documento sobre Güemes y San Martín es una muestra de esto, ya que Mitre, en primer lugar, evita manifestar sorpresa frente a una fuente que indudablemente desconocía; y en segundo lugar, procura restarle importancia y de paso mostrar su erudición en la materia. Como contrapartida, también Peña estaba intentando hacerse un lugar en el mundillo historiográfico, al buscar llamar la atención del más prestigioso historiador del momento, por lo cual, recibir una respuesta ya era considerado valioso, aunque ésta encerrara una negativa. Porque la posibilidad de entablar este diálogo epistolar era ya en sí misma considerada importante, escribió muchos años más tarde en un texto de carácter autobiográfico, y refiriéndose a sí mismo en tercera persona: "Mitre

\footnotetext{
${ }^{31}$ AANH, FDP, c. 1, David Peña a Bartolomé Mitre, 26 de junio de 1900.

32 AANH, FDP, c. 1, Bartolomé Mitre a David Peña, 3 de julio de 1900.

${ }^{33}$ A. Eujanian, "El surgimiento", 18.
} 
contestó [a Peña] su correspondencia siempre con atención y recibiólo con distinción y cortesía, en pleno conocimiento de su adhesión ilimitada por Alberdi". ${ }^{34}$

\section{El momento crucial: el Juan Facundo Quiroga y los herederos de Mitre}

Tal como se ha adelantado, en el desempeño de sus funciones como profesor suplente de Historia Argentina en la Facultad de Filosofía y Letras, David Peña pronunció en 1903 unas conferencias acerca del tema del caudillismo y de la figura del caudillo riojano Juan Facundo Quiroga que se hicieron famosas. Estas, y el libro al que dieron lugar al ser publicadas en 1906, constituyen sin duda el episodio más resonado y polémico de toda su trayectoria como historiador. En ese escrito, Peña se anima a refutar los juicios sentados por Sarmiento en Facundo y a restaurar la memoria del caudillo frente a la imagen negativa que sobre él había tejido la tradición liberal. Presenta a Quiroga como un genuino representante del sistema federativo, partidario de la sanción de una constitución y de la organización definitiva de la república.

No se pretende ahondar aquí en el contexto, características y repercusiones de la obra de Peña, los que ya han sido abordados en otra oportunidad. ${ }^{35}$ Pero lo que sí interesa destacar, en el marco del análisis sobre el posicionamiento de Peña frente al mitrismo, es que para el momento de la publicación Bartolomé Mitre acababa de fallecer, de modo que fue uno de sus epígonos el que levantó su bandera frente a la aparición del libro. Desde las columnas de La Nación -el diario fundado por el ex presidente en 1870- su nieto Jorge Mitre exclamó: "Deploramos la perniciosa enseñanza que puede inculcar en el espíritu desprevenido del pueblo, la representación de esta obra, sutil y talentosa, pero profundamente falsa". ${ }^{36}$

En lo personal, no obstante, la relación de David Peña con los sucesores de Mitre no dejaba de ser cordial, y en particular mantuvo un vínculo de amistad con Emilio Mitre (1853-1909), quien fue ingeniero, periodista y director de La Nación entre 1894 y 1909. En el Fondo David Peña de la AANH existen dos cartas, sin fecha precisa, dirigidas por el hijo de Bartolomé a Peña. En ambas se evidencia la misma discordancia de su padre, ante los pedidos de este, a pesar de la amistad que los unía. En una de esas cartas, Emilio Mitre se excusa ante una solicitud cursada por Peña con respecto a uno de sus libros, alegando que no ha podido terminar de leer el texto por falta de tiempo, y que no le gusta el personaje. En la otra misiva, procura disuadirlo a Peña de hacer públicos ciertos errores en los que habría caído el influyente político e intelectual Estanislao Zeballos, y que aquel había advertido. ${ }^{37}$

El conjunto de cartas intercambiadas con los Mitre permite visualizar que, más allá de que posteriormente haya sido considerado un precursor del revisionismo histórico argentino por sus planteamientos acerca del caudillismo y de otras cuestiones -

\footnotetext{
${ }^{34}$ AANH, FDP, c. 12, "Prospecto. Obras de Historia Argentina del Dr. David Peña".

35 María Gabriela Micheletti, “Facundo Quiroga rehabilitado'. Una aproximación al contexto de producción, repercusiones y aportes historiográficos del libro de David Peña (1906)", Boletín del Instituto de Historia Argentina y Americana “Dr. Emilio Ravignani”, 42 (2015): 125-153.

${ }^{36}$ Cit. en Armando Raúl Bazán, "La historiografía riojana. Desde Sarmiento a David Peña. El esquema ideológico de 'civilización y barbarie', influencia y refutación”, Investigaciones y ensayos, 29 (1980): 141.

${ }^{37}$ AANH, FDP, c. 12, Emilio Mitre a David Peña, 6 de agosto y 25 de marzo, s/año.
} 
como la defensa de Alberdi frente a la Guerra de la Triple Alianza-, Peña tuvo por referente a Bartolomé Mitre, cuyo apoyo y opinión, sobre todo en sus años de juventud, buscó y valoró. ${ }^{38}$ Es decir, aunque en sus escritos Peña planteó tópicos que luego serían retomados y desarrollados por el movimiento revisionista, su pensamiento -reflejado tanto en sus textos de carácter público como en su correspondencia privada- no parece haber pretendido ni supuesto una ruptura con la tradición historiográfica liberal, al menos, en cuanto a la intencionalidad puesta de manifiesto por el autor. ${ }^{39}$ Hay que agregar, además, que la defensa de Juan Manuel de Rosas, uno de los temas más recurrentes del posterior revisionismo, no se encuentra presente en la obra de Peña, quien mantuvo -en clara sintonía en este aspecto con la tradición liberal- una postura de abierta condena.

Las tensiones que despuntaban entre su posicionamiento y el del mitrismo, sin embargo, no pasaron desapercibidas entre sus mismos contemporáneos. Puede resultar sintomático que sólo algunos meses después del deceso de Mitre - pero no antes-, haya sido admitida la incorporación de Peña como miembro de número a la Junta de Historia y Numismática Americana (actual Academia Nacional de la Historia), institución que a modo de tertulia académica aquel había iniciado junto a algunos otros eruditos hacia 1893. ${ }^{40}$ Esta incorporación, además, resultó accidentada: debido a ella un miembro renunció y otros, sin llegar a ese extremo, expresaron sus reparos, como el político e historiador correntino Manuel F. Mantilla (1853-1909), de reconocida adscripción liberal mitrista, que sostuvo que el libro de Peña sobre Quiroga encerraba "apreciaciones y citas erróneas" y estaba escrito "con un criterio completamente equivocado". 41

Todavía muchos años después, la presencia de David Peña en la Junta de Historia y Numismática Americana sería interpretada por su amigo Francisco Barroetaveña (1856-1933) como una verdadera avanzada en tierra "enemiga". Las expresiones vertidas en la intimidad de la correspondencia no tienen desperdicio en cuanto permiten apreciar hasta qué punto la posición historiográfica de Peña era evaluada como divergente a la sostenida por la tradición mitrista, todavía fuerte en la Junta a principios de la década del veinte:

Estimado amigo: La noticia de La Nación sobre su memoria a la "Numismática", me ha dejado con ganas de conocerla [...] ;Admiro no solo el talento del autor, sino la política florentina con que ha filtrado en aquel templo enemigo su proceso histórico, tan bien

\footnotetext{
${ }^{38}$ Fernando Devoto ha clasificado a las obras de David Peña, Adolfo Saldías y Ernesto Quesada, dentro de un posible "revisionismo" anterior al denominado revisionismo histórico que hizo eclosión en la Argentina en los años treinta del siglo XX. En todo caso, es importante resaltar que la revisión de la historia que estos historiadores promovieron, en tanto que operación historiográfica -la aplicación de un método basado en la objetividad histórica y la compulsa documental-, se diferenció de la operación política que supuso el revisionismo de los años 30 como impugnación del liberalismo y democratismo del sistema republicano argentino. F. Devoto y N. Pagano, Historia, 203-205; y J. C. Chiaramonte, "Revisión del revisionismo", 145-179.

${ }^{39}$ En su obra, Peña cita en diversas ocasiones al "ilustrado autor de la Historia de Belgrano". D. Peña, Contribución al estudio, 54.

${ }^{40}$ Aurora Ravina, "La fundación, el impulso mitrista y la definición de los rasgos institucionales", en $L a$ Junta de Historia y Numismática Americana y el movimiento historiográfico en la Argentina (18931938), t. I (Buenos Aires: ANH, 1995).

${ }^{41}$ Boletín de la Junta de Historia y Numismática Americana (BJHNA), 4 (1927): 329-330 y 332.
} 
basado y disfrazado, que se le tolera y hasta se publica el contenido en la Biblia de la Secta! ${ }^{42}$

Resulta interesante ver que Barroetaveña, un radical consustanciado con el liberalismo laicista y anticlerical, utilizaba varias imágenes y metáforas de contenido religioso para descalificar a la Junta. Esta era un "templo", y el mitrismo era una "secta" cuyas enseñanzas se difundían a través de un periódico, La Nación, que actuaba a modo de libro sagrado, impartiendo una palabra dogmática que no podía ser puesta en cuestión. La queja de Peña no se hizo esperar, ofendido de que su amigo lo acusara de engañar, cuando siempre había procurado defender la verdad histórica, así como de ser un infiltrado, en una institución que había ayudado a organizar desde sus primeros tiempos. ${ }^{43}$ Su disgusto obligó a Barroetaveña a explicar el alcance de sus afirmaciones y a pedir disculpas por su exabrupto:

La intención fue felicitarle por el ingenio para hablar así en casa de Mitre y bajo la presidencia de Cárcano, donde se precisaba destreza para alcanzar éxito, como lo tuvo. No basta tener razón histórica y hablar con lógica y altivez, pues ya ve Ud. que no admiten elogios de Alberdi ni de Urquiza en ninguna medida. Pero habré estado estúpido para expresarme en forma hiriente, cuando quería hacer un elogio. Dispense la barbaridad. ${ }^{44}$

Para entonces habían pasado catorce años desde la muerte de Mitre, pero la Junta seguía siendo considerada su "casa", por la continuidad que significaba la presencia de historiadores que mantenían la tradición historiográfica, como era el caso de Ramón Cárcano como presidente de la institución. Por ello, voces como la de David Peña seguían sonando discordantes, debido a sus intentos por revisar la construcción histórica que sobre determinados personajes del pasado había sido fijada por el mitrismo. Alberdi era quizá el caso más emblemático por su enemistad personal con Mitre, pero también lo eran Quiroga, Urquiza y Dorrego, entre otras figuras que Peña se había ocupado de estudiar y presentar despojadas de los rótulos negativos que les había conferido la historia.

\section{La proyección a través de los vínculos con historiadores "revisionistas"}

Si en sus años de juventud, David Peña buscó el respaldo y reconocimiento de Bartolomé Mitre, en el archivo de su correspondencia personal es posible advertir que, con el paso del tiempo, fue trabando relación con una serie de historiadores que desde fines del siglo XIX y comienzos del XX iniciaron, al igual que él, un proceso de revisión histórica. Algunos, al igual que Peña, han contribuido a delinear un llamado "primer revisionismo". ${ }^{45}$ Otros, por sus escritos y planteamientos de la época del positivismo (aproximadamente 1880-1910), han recibido el nombre de "positivistas" o,

\footnotetext{
42 AANH, FDP, c. 2, Francisco Barroetaveña a David Peña, 14 de septiembre de 1920.

43 Para una síntesis de los aportes realizados por Peña a la Junta: María Gabriela Micheletti, "Los primeros santafesinos de la Junta de Historia y Numismática Americana. Consideraciones en torno a la personalidad y labor de cuatro intelectuales notables", Revista de la Junta Provincial de Estudios Históricos de Santa Fe, 69 (2011): 75-104.

${ }_{44}^{4}$ AANH, FDP, c. 2, Francisco Barroetaveña a David Peña, 21 de septiembre de 1920.

${ }^{45}$ J. C. Chiaramonte, "Revisión del revisionismo", 145-179.
} 
mejor, de enrolados en las filas de la "cultura científica". ${ }^{46}$ Otros, concurrieron a dar forma al movimiento nacionalista.

Precursor del revisionismo fue Adolfo Saldías (1849-1914), que escribió a Peña en 1906, para manifestarle su parecer acerca del Quiroga. En su carta, Saldías se muestra entusiasmado con un libro que venía a continuar la obra de revisión de la tradición federal, encarada por él hacía más de veinte años:

\begin{abstract}
Quiroga -como Ramírez- con su altruismo generoso, con los yerros en el camino erizado de sus peregrinaciones patrióticas, espera la justicia de la historia. En este sentido Ud. ha contribuido en buena ley a iluminar el cuadro en el cual los jóvenes, sin preocupaciones anacrónicas, encontrarán las verdaderas luces y las verdaderas sombras para decidir del mérito que tenga ese argentino ante la posteridad $[\ldots] .^{47}$
\end{abstract}

Aunque se trata del hallazgo de una única carta intercambiada entre estos dos historiadores, ${ }^{48}$ ella resulta sugerente en cuanto pone en relación a dos historiadores polémicos, que fueron en su momento cuestionados -Saldías, más que Peña- por su visión de la historia. ${ }^{49}$ También es importante destacar que, según el entender de Saldías, el mayor mérito de Peña radica en haber abierto un camino que seguirían otros. El contacto epistolar se reanudará, años más tarde, a través del hijo del historiador de Rosas. José Antonio Saldías escribe a Peña para pedirle el parecer sobre su drama histórico Romance federal, poco antes de su estreno en 1928. Peña procura ser amable pero es severo en la crítica y pone en duda el carácter histórico de diversos pasajes, lo que hace adoptar a José Antonio un tono ofendido en su misiva de respuesta. Lo interesante es que en esta, más allá del descargo que hace, Saldías (hijo) evoca el ejemplo dado por su padre y por Peña, como móvil de su propia audacia y empeño en que "revisemos nuestra fábula histórica" ${ }^{50}$ Como se advierte, las cartas de ambos Saldías rescatan el rol desempeñado por Peña en la construcción de una imagen alternativa del caudillismo y del federalismo, por fuera de la versión dominante.

También el médico y sociólogo socialista José Ingenieros (1877-1925), considerado como uno de los principales exponentes del positivismo en Argentina, demuestra interés con motivo de la aparición del Quiroga. En una carta a su autor manifiesta que comparte similares puntos de vista acerca del caudillismo y del federalismo, y ofrece confeccionar una reseña bibliográfica para alguna revista $o$ periódico europeo:

\footnotetext{
${ }^{46}$ Por "cultura científica" se designa al conjunto de intervenciones teóricas que reconocen el prestigio de la ciencia como dadora de legitimidad de sus propias argumentaciones. Oscar Terán, Vida intelectual en el Buenos Aires fin-de-siglo (1880-1910). Derivas de la "cultura cientifica” (Buenos Aires: FCE, 2008), 9.

${ }^{47}$ AANH, FDP, c. 1, Adolfo Saldías a David Peña, Buenos Aires, 24 de mayo de 1906.

${ }^{48}$ Según referencias, los vínculos con Saldías venían de lejos, de la época en la que éste frecuentaba la casa en la que un todavía niño David Peña habitaba con un tío en Buenos Aires. L. Kanner, David Peña, 47.

${ }^{49}$ Saldías publicó su Historia de Rosas y de su época en tres tomos (1881, 1884 y 1887), que luego amplió en Historia de la Confederación Argentina (1892, 5 tomos). Aunque liberal y seguidor de Mitre, su trabajo heurístico lo condujo a presentar una imagen justificatoria de Rosas. Esta situación le valió el cuestionamiento por parte de Mitre y el silenciamiento en el ambiente intelectual y periodístico.

${ }^{50}$ AANH, FDP, c. 3, José Antonio Saldías a David Peña, s/f, David Peña a José A. Saldías, 14 de abril de 1928, José A. Saldías a David Peña, 17 de abril de 1928 y José A. Saldías a David Peña, 19 de abril de 1928.
} 
Por los diarios de Buenos Aires he sabido el éxito de su Quiroga. Me interesa mucho; en mis escritos de crítica sociológica argentina (que seguramente usted no conoce) me he manifestado siempre partidario de la revisión del proceso histórico a Rosas, Quiroga y los federales, difamados durante medio siglo por los escritores unitarios. ${ }^{51}$

Peña e Ingenieros mantenían una relación de amistad previa, y esta se prolongó en el tiempo, como lo demuestra una serie de cartas intercambiadas a lo largo de las décadas del diez y del veinte, en las que salen a luz diversos temas de interés común a estos dos intelectuales, que departen sobre publicaciones y revistas, escritos y asociaciones culturales. Volcado a los estudios de Filosofía durante su auto exilio en Europa (1911-1914), a su regreso al país Ingenieros dirigió la Revista de Filosofía. Para ella le solicita a Peña en 1918 una colaboración, "sobre Alberdi, por ejemplo". ${ }^{52}$ Los temas de interés de Peña son recurrentes y sus allegados lo saben, de ahí que tanto Ingenieros como Barroetaveña le hablen de su dedicación por Alberdi. La invitación de Ingenieros, abriéndole un canal para difundir su defensa alberdiana en contra de la imagen construida por el mitrismo, así como el ofrecimiento anterior de dar a conocer su obra sobre Quiroga a través de un comentario bibliográfico, sirven para evidenciar las estrategias utilizadas por esos historiadores "revisionistas" a fin de fortalecerse y respaldarse mutuamente frente a la tradición hegemónica.

David Peña mantuvo relación personal y epistolar, asimismo, con otro de los precursores del revisionismo e historiador de la etapa positivista. Se trata de Ernesto Quesada (1858-1934), el autor de La época de Rosas, ${ }^{53}$ quien cultivó entre 1916 y 1920 un denso intercambio con Peña a través de cartas que se ocupan de cuestiones culturales, como asociaciones, conferencias, revistas y escritos. ${ }^{54}$ Varias cartas mencionan a asociaciones de carácter cultural y/o historiográfico, como el Ateneo Nacional (fundado por Peña), el Instituto Popular de Conferencias del diario La Prensa, la Academia Argentina de la Lengua (de la que era director Quesada) y la Junta de Historia y Numismática Americana (a la que pertenecían ambos). Los ámbitos de sociabilidad intelectual parecen haber contribuido a estrechar los vínculos entre ambos historiadores, que además compartían como docentes universitarios los mismos espacios de formación académica, en las universidades de Buenos Aires y de La Plata. A veces, las cartas se dedican a mencionar escritos propios o ajenos, publicados en revistas culturales como Nosotros y la Revista de la Universidad, o en periódicos como La Razón y La Unión y, también, a intercambiar o comentar libros. ${ }^{55}$

\footnotetext{
${ }^{51}$ AANH, FDP, c. 1, José Ingenieros a David Peña, París, 1906.

${ }^{52}$ AANH, FDP, c. 2, José Ingenieros a David Peña, 13 de marzo de 1918.

53 Además de constituir una justificación documentada de Juan Manuel de Rosas, La época de Rosas (1898) es una obra positivista en el sentido de que está dominada por una perspectiva sociológica y son factores profundos los que explican el devenir histórico; así, Rosas es explicado como una consecuencia de las características de la sociabilidad argentina. F. Devoto y N. Pagano, Historia, 92-96.

${ }^{54}$ AANH, FDP, c. 1, Ernesto Quesada a David Peña, 12 de abril de 1916, y c. 2, Ernesto Quesada a David Peña, 10 de julio de 1917, 10 de agosto de 1917, y 8 de abril de 1918, entre otras. Ernesto Quesada y su padre Vicente fueron notables bibliófilos y promotores de varias iniciativas culturales vinculadas a la creación de revistas e instituciones. Véase Pablo Buchbinder, Los Quesada. Letras, ciencias y política en la Argentina, 1850-1934 (Buenos Aires: Edhasa, 2012).

${ }^{55}$ AANH, FDP, c. 2, Ernesto Quesada a David Peña, 10 de agosto de 1917, 8 de abril de 1918, y 10 de septiembre de 1920.
} 
En contraste con el rico intercambio epistolar con historiadores "revisionistas" positivistas, como Ingenieros y Quesada, la correspondencia entre Peña y algunos "revisionistas" nacionalistas resulta más esporádica, tal vez debido a una mayor distancia generacional e ideológica. Ricardo Rojas (1882-1957), que formó parte del nacionalismo cultural argentino que hizo eclosión para el Centenario de Mayo, ${ }^{56}$ contacta en 1916 con Peña a través de una nota, por la que declina la invitación a participar en un ciclo de lecturas en el Ateneo. ${ }^{57}$ De todos modos, a pesar del escaso rastro epistolar, al autor de La restauración nacionalista (1909) y a Peña parece haberlos unido una relación que se haría extensiva a sus familias y que se prolongaría en el tiempo, más allá de la muerte de Peña. ${ }^{58}$ No es fácil encontrar entre ambos, en cambio, demasiadas afinidades en cuanto a la interpretación del pasado, ya que la posición de Peña, que desde un marco liberal se ceñía a revisar la imagen de algunas figuras del pasado, como la de Alberdi o la de los caudillos provinciales, distaba bastante del fuerte componente patriótico y de la recuperación de las herencias hispana e indiana presentes en la obra de Rojas, aunque esta también supusiera la revalorización de la tradición federal.

Con Carlos Ibarguren (1877-1956), la documentación hallada se limita a una carta formal de 1917 -escrita aún bajo su etapa liberal-, en la que lamenta no poder satisfacer a Peña con un trabajo histórico sobre el año 1813, tema al que por ese entonces dedicaba sus clases en la Facultad de Filosofía y Letras pero sin haber puesto aún por escrito sus lecciones. ${ }^{59}$

Una carta más tardía, de 1928, da cuenta del contacto epistolar con Manuel Gálvez (1882-1962). Sobrino del ex gobernador santafesino José Gálvez, Manuel había frecuentado a David Peña desde pequeño y trabado una relación que lo llevaría a reconocer en él a uno de sus "maestros". ${ }^{60}$ En la carta mencionada, en la que se alude a escritos literarios de ambos autores, ${ }^{61}$ nada se insinúa sobre cuestiones históricas, ni sobre las posiciones de revisión del pasado que, salvando las distancias -ya que Peña las había emprendido desde el liberalismo, y Gálvez las adoptaría desde el nacionalismo católico-podían llegar a vincular a ambos autores.

Por último, merece una mención la correspondencia mantenida con dos autores paraguayos consagrados a la revisión de su propio pasado patrio: Juan E. O’Leary

\footnotetext{
${ }^{56}$ El nacionalismo cultural argentino buscó elaborar un relato del pasado con fines pedagógicos y patrióticos, y el debate político-cultural que se produjo para la época fue acompañado por un proceso de revisión histórica. Para profundizar sobre el clima cultural e historiográfico en el momento del Centenario y el rol desempeñado por Ricardo Rojas: Fernando Devoto, "Entre ciencia, pedagogía patriótica y mito de los orígenes. El momento de surgimiento de la historiografía profesional argentina", en Estudios de historiografía argentina (II) (Buenos Aires: Biblos, 1999), 11-34.

${ }^{57}$ AANH, FDP, c. 1, Ricardo Rojas a David Peña, 30 de abril de 1916.

58 AANH, FDP, c. 3, Ricardo Rojas a Octavio Amadeo y sra., 27 de diciembre de 1954. La esposa de Octavio Amadeo era Fidela Peña, hija de David. Rojas les escribe para darles el pésame por el fallecimiento de Fernando Peña, hermano de Fidela.

${ }^{59}$ AANH, FDP, c. 2, Carlos Ibarguren a David Peña, 14 de septiembre de 1917.

${ }^{60}$ Véase Manuel Gálvez, Recuerdos de la vida literaria (1900-1910). Amigos y maestros de mi juventud (Buenos Aires: Editorial Kraft, 1946).

${ }^{61}$ AANH, FDP, c. 3, David Peña a Manuel Gálvez, 16 de octubre de 1928.
} 
(1879-1969) y su discípulo Juan Stefanich (1889-1976). ${ }^{62}$ En este caso, el género epistolar ayuda a cruzar las fronteras nacionales y a poner en relación con Peña, a principios de 1907, a un O'Leary entusiasmado por la lectura del Juan Facundo Quiroga debido al proceso de revisión histórica que éste supone. ${ }^{63}$ Luego de varios años se reanuda el contacto epistolar, esta vez en torno a la figura de Alberdi, cuya memoria también reivindicaban los paraguayos debido a su postura frente a la Guerra. Tanto Peña como O’Leary publicaron, a fines de la década de 1910, artículos periodísticos en defensa de Alberdi, y a raíz de ellos volvieron a escribirse. Por su parte, Juan Stefanich - presidente del Centro de Estudiantes de Derecho de la Universidad Nacional de Asunción - tuvo la oportunidad de participar junto con una delegación de estudiantes paraguayos, y a invitación de Peña, en los actos de homenaje a Alberdi que se llevaron a cabo en Buenos Aires en 1920. ${ }^{64}$ La relación epistolar se mantiene todavía en 1928. Para entonces, O’Leary -quien ya había concretado la publicación de su biografía reivindicatoria del mariscal Francisco Solano López (1920)- se refiere a Peña en una carta como: "el gran justiciero de la historia argentina, el intrépido vindicador de la memoria de Alberdi, el que arrojó las primeras flores de piadosa recordación sobre la tumba sin nombre de Facundo Quiroga". 65 En breves líneas, el paraguayo lograba distinguir el rol cumplido por Peña en la revisión de la tradición inaugurada por Bartolomé Mitre en la escritura de la historia argentina.

\section{Consideraciones finales}

La consulta del epistolario de David Peña resulta enriquecedora en varios aspectos. En primer lugar, porque permite advertir la variedad de los contactos entablados -analizados en este artículo solo en parte-, con numerosas personalidades de la cultura del período de entresiglos (ss. XIX al XX). En segundo lugar, porque revela la amplitud de ideas de Peña para relacionarse con diversos letrados, más allá de las diferencias generacionales e ideológicas. En tercer lugar, porque refleja las prácticas de un estadio historiográfico en el que a través de vínculos interpersonales se hacían circular libros, escritos y documentos, se programaban conferencias, se articulaban comisiones de homenaje, se debatía pero también se buscaban acuerdos, y en el que apenas comenzaban a despuntar las primeras instituciones y los límites entre las distintas disciplinas o campos del saber aún aparecían difusos, en el marco de un todavía incipiente proceso de profesionalización de la historia. En cuarto lugar, bucear en el archivo epistolar de David Peña es interesante, porque permite conocer mejor los mecanismos y estrategias utilizados por este intelectual nacido en Rosario para hacerse un lugar en el mundo intelectual porteño; entre ellos, sus esfuerzos por atraer la atención de Bartolomé Mitre, principal figura de la historiografía nacional decimonónica.

\footnotetext{
62 Estos contactos han sido estudiados con mayor detalle en: Liliana M. Brezzo y María Gabriela Micheletti, "Libros, cartas, lecturas. La revisión de la historia en Argentina y Paraguay a través de los intercambios epistolares entre David Peña y Juan E. O’Leary”. História da Historiografia, 20 (2016): 1430 .

${ }^{63}$ Biblioteca Nacional del Paraguay (BNP), Colección Juan E. O’Leary (CJOL), Juan E. O’Leary a David Peña, Asunción, enero de 1907.

${ }^{64}$ AANH, FDP, c. 2, David Peña a Juan Stefanich, 20 de abril de 1919, y Juan Stefanich a David Peña, Asunción, 21 de mayo de 1920.

${ }^{65}$ AANH, FDP, c. 3, Juan E. O’Leary a David Peña, Madrid, 28 de agosto de 1928.
} 
En el intercambio epistolar Peña-Mitre se hace manifiesta la asimetría existente entre ambos interlocutores, así como los intentos de aproximación encarados por Peña, en un gesto que deja al descubierto el reconocimiento tributado por parte del joven historiador a quien se reconoce como una autoridad en materia historiográfica. Nada en estas cartas hace suponer ruptura, ni repudio hacia una manera de interpretar el pasado, tal como lo planteó el posterior revisionismo histórico. Sí se advierte, en cambio, la autonomía de Peña para sostenerse en ciertas ideas por fuera de la tradición mitrista, en lo que puede encontrarse su herencia alberdiana. Es esta posición independiente la que es puesta en evidencia ya por algunos de sus contemporáneos, como Barroetaveña, y leída en clave de oposición, en forma similar a como sería leída más tarde por los mismos revisionistas.

Por otro lado, el ramillete de cartas intercambiadas entre Peña y otros escritores comprometidos en posiciones de revisión histórica, dan indicios de cómo ellos mismos buscaron contactarse, poner en relación sus escritos y visiones sobre el pasado, y también respaldarse mutuamente en la empresa de reivindicación. Se hace patente la necesidad de confiarse las propias ideas y de poner en relieve las coincidencias, y también de tejer amistades trabadas por consensos historiográficos. En algunos casos, como con Ingenieros o Saldías, las amistades eran previas y excedieron a la preocupación por la escritura de la historia, aunque es probable que el vínculo se haya visto reforzado por esa sintonía intelectual. En otros casos, los contactos surgieron al calor de dicha escritura, como en la relación entablada con los paraguayos O'Leary y Stefanich. En este último caso, también resulta interesante señalar el disímil derrotero que siguió el proceso de revisión de la historia iniciado en ambos países. Ya que mientras la construcción historiográfica de Peña se erigió como un discurso lateral, que entraba en fricción con el discurso histórico provisto desde la tradición liberal mitrista dominante, y por ello fue más tarde recuperada por el revisionismo antiliberal e impugnador de la "historia oficial" argentina, el discurso de O'Leary -de alto componente reivindicativo- fue asumido por el Estado paraguayo y se transformó en la historia hegemónica durante los largos años del stronato. ${ }^{66}$

Las cartas contribuyen asimismo a visualizar cuáles fueron los personajes de la historia en torno de los cuales se dieron los principales acuerdos entre Peña y sus corresponsales: Quiroga y los caudillos provinciales, Urquiza, Alberdi, y hasta Francisco Solano López. No así Rosas, figura frente a la cual se impuso en Peña la tradición liberal mitrista, y ante la cual plantó un límite a su propio proceso de revisión histórica.

De esta manera, y consideradas en conjunto con el resto de su producción histórica, las cartas de Peña -tanto las enviadas, como las recibidas por él-ayudan a precisar mejor los contornos de su posicionamiento historiográfico, anclado en la tradición liberal decimonónica, pero a la vez, atravesado por novedosas perspectivas,

\footnotetext{
${ }^{66}$ Liliana Brezzo ha señalado las características peculiares del denominado "revisionismo histórico paraguayo" y ha planteado la inconveniencia, desde la perspectiva de la interpretación del pasado, de la aplicación de ese concepto para el caso de Paraguay. Liliana M. Brezzo, "¿Qué revisionismo histórico? El intercambio entre Juan O'Leary y el Mariscal Pietro Badoglio en torno a El Centauro de Ybycuí", en Paraguay en la historia, la literatura y en la Memoria, ed. Juan Manuel Casal y Thomas L. Whigham, (Montevideo, Asunción: Universidad de Montevideo y Editorial Tiempo de Historia, 2011), 361-375.
} 
que lo hacen estar alerta frente a las innovaciones que se van produciendo, y lo ponen en contacto con quienes las impulsan, historiadores embarcados al igual que él -aunque desde variados enfoques- en posiciones "revisionistas". Su temprana defensa de Juan Bautista Alberdi y su precursora reivindicación del caudillo Facundo Quiroga operan, al respecto, como fuerzas que contribuyen a dinamizar y dotar de sentido al contenido de su epistolario y que lo posicionan a Peña en un lugar central de las disputas por la construcción historiográfica del pasado argentino.

\section{Profile}

Profesora, Licenciada y Doctora en Historia. Investigadora del Consejo Nacional de Investigaciones Científicas y Técnicas (CONICET, Argentina), y docente de la Universidad Católica Argentina. Autora de los libros La universidad en la mira. La "Laica o Libre" y sus expresiones rosarinas, 1955-1959 (Imago Mundi, 2013), Historiadores e historias escritas en entresiglos. Sociabilidades y representaciones del pasado santafesino, 1881-1907 (Lumière, 2013), y Escribir la nación en las provincias (IDEHESI, 2013, en co-autoría).

Professor, License and Doctor in History. Researcher of the National Council of Scientific and Technical Research (CONICET, Argentina), and Professor at the Universidad Católica Argentina. Author of the books La universidad en la mira. La "Laica o Libre" y sus expresiones rosarinas, 1955-1959 (Imago Mundi, 2013), Historiadores e historias escritas en entresiglos. Sociabilidades y representaciones del pasado santafesino, 1881-1907 (Lumière, 2013), and Escribir la nación en las provincias (IDEHESI, 2013, in co-authoring).

Fecha de recepción: 5 de julio de 2018.

Fecha de aceptación: 29 de noviembre de 2018.

Publicación: 31 de diciembre de 2018.

Para citar este artículo: María Gabriela Micheletti, "Entre la tradición liberal y la revisión histórica. La construcción del pasado argentino a través de la correspondencia privada del historiador David Peña (1862-1930)", Historiografías, 16 (julio-diciembre, 2018): pp. 57-75. 